\title{
Identification of clear cell renal cell \\ (1) Consumate carcinoma and oncocytoma using a three-gene promoter methylation panel
}

\author{
Ana Sílvia Pires-Luís ${ }^{1,2}$, Pedro Costa-Pinheiro ${ }^{1}$, Maria João Ferreira' ${ }^{1}$ Luís Antunes ${ }^{3}$, Francisco Lobo ${ }^{4}$, \\ Jorge Oliveira ${ }^{4}$, Rui Henrique ${ }^{1,2,5 \dagger}$ and Carmen Jerónimo ${ }^{1,5^{*}}$ (D)
}

\begin{abstract}
Background: Promoter methylation has emerged as a promising class of epigenetic biomarkers for diagnosis and prognosis of renal cell tumors (RCTs). Although differential gene promoter methylation patterns have been reported for the major subtypes (clear cell, papillary and chromophobe renal cell carcinoma, and oncocytoma), validation of diagnostic performance in independent series have been seldom performed. Herein, we aimed at assessing the diagnostic performance of genes previously shown to be hypermethylated in RCTs in different clinical settings.

Methods: Promoter methylation levels of HOXA9 and OXR1 were assessed by quantitative methylation specific PCR. ROC curves were generated for OXR1, OXR1 combined with MST1R and HOXA9. Sensitivity, specificity, positive predictive value, negative predictive value and accuracy were computed, maximizing specificity. Methylation levels were also correlated with clinical and pathological relevant parameters.

Results: HOXA9 and OXR1 promoter methylation was disclosed in 73 and $87 \%$ of RCTs, respectively. A two-gene methylation panel comprising OXR1 and MST1R identified malignancy with 98\% sensitivity and 100\% specificity, and clear cell renal cell carcinoma with 90\% sensitivity and 98\% specificity. HOXA9 promoter methylation allowed for discrimination between oncocytoma and both papillary and chromophobe renal cell carcinoma but only with $77 \%$ sensitivity and 73\% specificity. Significantly higher OXR1 promoter methylation levels ( $p=0.005)$ were associated with high nuclear grade in ccRCC.

Conclusions: A panel including OXR1 and MST1R promoter methylation allows specific and sensitive identification of renal cell tumors, and, especially, of clear cell renal cell carcinoma. Moreover, higher OXR1 promoter methylation levels associate with clear cell renal cell carcinoma nuclear grade, a surrogate for tumor aggressiveness. Thus, gene promoter methylation analysis might a useful ancillary tool in diagnostic management of renal masses.
\end{abstract}

Keywords: Kidney tumours, Renal cell tumour, Clear cell renal cell carcinoma, Oncocytoma, Epigenetics, Methylation, OXR1, HOXA9, MST1R, Diagnostic biomarker

\section{Background}

Epigenetic deregulation is a frequent finding in renal cell tumors (RCT) [1]. These arise from renal cortical tubular

\footnotetext{
*Correspondence: carmenjeronimo@ipoporto.min-saude.pt; cljeronimo@icbas.up.pt

${ }^{\dagger}$ Rui Henrique and Carmen Jerónimo are Joint senior authors ${ }^{1}$ Cancer Biology and Epigenetics Group, IPO Porto Research Center (CI-IPOP), Portuguese Oncology Institute of Porto (IPO Porto), Research Center-LAB 3, F Bdg., 1st Floor, Rua Dr António Bernardino de Almeida, 4200-072 Porto, Portugal

Full list of author information is available at the end of the article
}

cells and encompass several entities, the most frequent being clear cell renal cell carcinoma (ccRCC), papillary renal cell carcinoma (pRCC) and chromophobe renal cell carcinoma (chRCC), representing 75, 10-15 and 5\% of all RCT respectively. These are malignant neoplasm, although of variable aggressiveness. Indeed, ccRCC and pRCC are those that most frequently progress through regional and systemic metastization, whereas chRCC is generally more indolent. Among benign tumors, the most frequent RCT is oncocytoma [2]. 
The differential diagnosis among specific RCT subtypes can be challenging, especially in those tumors composed of cells with granular eosinophilic cytoplasm, as some morphological and immunohistochemical overlap exists among oncocytoma, eosinophilic variant of chRCC and eosinophilic variant of ccRCC $[2,3]$. However, since their prognosis is radically different, accurate discrimination among these entities is critical. Furthermore, RCT therapy is becoming progressively more conservative, especially those of small size, with increasing use of cryoablation or radiofrequency techniques [4], entailing the need for more accurate diagnosis in biopsy samples. Owing to the heterogeneity that characterizes RCTs, a small tumor tissue sample might impair an accurate diagnosis based on histopathological, histochemical and immunohistochemical features $[4,5]$. In this context, epigenetic biomarkers may constitute a valuable ancillary tool for diagnosis in biopsies from renal masses.

Among epigenetic alterations, aberrant promoter methylation, which generally entails gene silencing [6], has emerged as a promising class of biomarkers in urologic neoplasms [7], including RCTs [8, 9]. Although several genes are known to be hypermethylated in RCTs, mostly in ccRCC [10], frequencies vary, with most genes displaying intermediate (20-70\%) methylation frequencies. Among genes with consistently high ( $>70 \%)$ methylation frequency in RCC, APAF1 [11, 12], MDR1 [13], and PTGS2 [13], should be highlighted (97-100, 86 and 94\%, respectively). Recently, we showed that MST1R was also frequently methylated in RCC, and promoter methylation levels discriminated ccRCC from the remaining RCT subtypes with high specificity [14].

Nevertheless, over the last years, several high-throughput studies on RCC promoter methylation using an array-based approach, identified several other hypermethylated genes in RCC, which might be useful as diagnostic biomarkers. This somewhat extensive list includes SPINT2 [15], IGFBP1, IGFBP3, COL1A1 [16], UCHL1 [17], CXCL16, KTN19 [18], IGFBP2, SOX17, COL1A2, BMP4, FRZB, TAL1, MCM2, KCNK4, HOXC6, CCNA1, HOXA11, TERT, TMEFF2, PGF, ZNF215, SMARCB1, TWIST1, IGFBP7 [19], BNC1, COL14A1, SFRP1 [20], $P C D H 8, C C D C 8$, and FBN2 [21]. Most of these studies, however, mostly focused on ccRCC, only, whereas other included the most frequent RCTs and identified specific methylation patterns for each subtype in general [22], or specifically for the distinction between chRCC and oncocytoma [23]. Still, diagnostic performance analysis of these putative RCT biomarkers has not been performed. Thus, we aimed to evaluate the diagnostic performance of promoter methylation of several genes previously identified as candidate RCT biomarkers in array studies
[22, 23], including also MST1R [14], in several differential diagnosis scenarios.

\section{Methods}

Patients, sample collection and DNA extraction

Representative tumor tissue was collected from 120 patients, submitted to radical or partial nephrectomy at the Portuguese Oncology Institute of Porto (Portugal) between 2003 and 2007, comprising ccRCC, pRCC, chRCC and oncocytoma (30 cases of each). Additionally, morphologically normal kidney (cortical) tissue from 9 nephrectomy specimens for upper urinary tract neoplasia were also collected and served as controls.

Tissue samples were snap-frozen immediately after surgery, stored at $-80^{\circ} \mathrm{C}$ and subsequently cut in a cryostat. The presence of at least $70 \%$ of tumor cells in the sections was assessed in H\&E stains. Genomic DNA extraction was performed as previously described [24]. Briefly, 10\% SDS was added to the sample, then proteinase K $(20 \mathrm{mg} /$ $\mathrm{mL}$, overnight, $55^{\circ} \mathrm{C}$ ) to digest DNA, followed by extraction with phenol-chloroform and precipitation with $100 \%$ ethanol.

Formalin-fixed paraffin-embedded routine sections were used for routine tumour classification and grading (WHO) as well as staging (TNM) [2]. Relevant clinical data was retrieved from clinical charts.

This study was approved by the Institutional Review Board (Comissão de Ética para a Saúde) of Portuguese Oncology Institute of Porto, Portugal (CES518/2010).

\section{Gene selection}

MST1R (GenBank: NM_002447) promoter methylation was previously identified by our group through EpiTect Methyl II qPCR array (SABiosciences, Qiagen, Frederick, MD, USA), and proved to be a specific diagnostic biomarker for ccRCC [14]. Briefly, 20 samples (4 ccRCC; 4 pRCC; 6 chRCC; 6 oncocytoma) were tested with the EMT commercial assay (Cat. No. 524EAHS-901ZA-24) on a 7000 Sequence Detection System (Applied Biosystems, Foster City, CA, USA) according to manufacturer instructions. MST1R, the gene with the highest percent of hypermethylated DNA (representing the fraction of input DNA containing at least two methylated CpG sites in the targeted region) was selected for further analysis, and proved to be a specific ccRCC biomarker [14].

Relevant literature was also reviewed, focusing on methylation array studies comparing different RCT subtypes, and two additional genes were selected: OXR1 (GenBank: NM_001198532.1), proposed as a promising diagnostic biomarker for proximal tubule-derived RCC (ccRCC and pRCC) [22]; and HOXA9 (GenBank: NM_152739.3) owing to its potential to distinguish chRCC from RO [23]. 


\section{Bisulfite treatment}

Bisulfite treatment to convert unmethylated cytosine to uracil, maintaining methylated cytosine as such, was performed with EZ DNA Methylation-Gold Kit (Zymo Research) according to the manufacturer's instructions, in 169 fresh-frozen samples: 9 morphologically normal kidneys, 30 ccRCC, 30 pRCC, 30 chRCC, 30 RO, 20 bladder urothelial carcinoma and 20 prostate adenocarcinoma samples.

\section{Quantitative MSP_fresh-frozen tissues}

Primers for the candidate genes were designed to amplify methylated bisulfite converted complementary sequences, using Methyl Primer Express v 1.0 (Applied Biosystems, Foster City, CA, USA), considering the best predicted primer pair for the promoter region of each gene. Primers are listed in Table 1 . A reference gene ( $\beta$-actin) was used to normalize for DNA input in each sample.

For fresh-frozen tissues, quantitative real-time polymerase chain reaction (qMSP) was performed in an 7500 Real-time PCR system (Applied Biosystems, Foster City, CA, USA), after DNA bisulfite treatment, in a reaction volume of $20 \mu \mathrm{L}$ consisting of $10 \mu \mathrm{L}$ of SYBR ${ }^{\circledR}$ Green PCR Master Mix (Applied Biosystems, Foster City, CA, USA), $7 \mu \mathrm{L}$ of $\mathrm{H}_{2} \mathrm{O}, 0.5 \mu \mathrm{L}$ of forward primer, $0.5 \mu \mathrm{L}$ of reverse primer and $2 \mu \mathrm{L}$ of bisulfate-modified DNA. Each sample was run in triplicate. In each plate, "no template controls" were included as a control for contamination, and a calibration curve was constructed with serial dilutions (1:5) of bisulfite converted universally methylated DNA at all CpGs (CpGenome Universal Methylated DNA; Millipore, Billerica, MA), to quantify the amount of fully methylated alleles in each reaction. The amplification reaction was carried out at $95{ }^{\circ} \mathrm{C}$ for $2 \mathrm{~min}$, then 45 cycles of $95{ }^{\circ} \mathrm{C}$ for $15 \mathrm{~s}$ and annealing temperature $\left(60{ }^{\circ} \mathrm{C}\right.$ for all genes) for $1 \mathrm{~min}$, followed by melting curve analysis.

For each sample, the relative level of methylated promoter DNA was determined by the ratio between the mean quantity obtained by qMSP analysis for each gene and the mean quantity of the internal reference gene $(A C T B)$, multiplied by 1000 for easy tabulation, according to the formula: methylation level $=$ (target gene/reference gene) $\times 1000$.

Table 1 Primer sequences used in quantitative methylation specific PCR for candidate genes

\begin{tabular}{lll}
\hline $\begin{array}{l}\text { Primer } \\
\text { set }\end{array}$ & $\begin{array}{l}\text { Sense primer sequence } \\
\left(5^{\prime}-\mathbf{3}^{\prime}\right)\end{array}$ & $\begin{array}{l}\text { Antisense primer sequence } \\
\left(\mathbf{5}^{\prime}-\mathbf{3}^{\prime}\right)\end{array}$ \\
\hline MST1R & AGCGTTAGTGTATAGCGGC & TAAACAACGATCCCGACA \\
OXR1 & TTCGTTGTATATATCGAACGGT & CCGTACTAAATATCTCGTTAACT \\
HOXA9 & TATTTAGTCGGATTCGC & ACCTCGAACGCTTCCAT \\
\hline
\end{tabular}

${ }^{a}$ MST1R promoter methylation primers from $[14,25]$

\section{Statistical analysis}

The frequency of methylated samples was determined for each RCT type, considering the highest value determined in the normal kidney tissue as cutoff. Median and interquartile range of methylation levels were also computed. Kruskal-Wallis non-parametric ANOVA followed by Mann-Whitney U test (with Bonferroni's correction) for pair-wise comparisons were used to identify significant differences in methylation levels among RCT subtypes and association with standard clinicopathological variables. Spearman's test was performed to ascertain correlation between age and methylation levels.

Methylation levels of OXR1 and MST1R were combined using a logistical regression model by computing a new variable with the predicted values.

To assess the performance of promoter methylation levels as diagnostic biomarkers, receiver operator characteristics (ROC) curves were constructed by plotting the true positive rate (sensitivity) against the false positivity rate (1-specificity), followed by computation of the area under the curve (AUC). Cutoff values based on ROC curve analysis, prioritizing specificity and then sensitivity, were selected for calculation of sensitivity, specificity, positive and negative predictive values, and accuracy.

Disease specific survival (time between diagnosis and death for renal cell carcinoma), disease free survival (time between treatment and the first metastasis or local recurrence) and overall survival (time between diagnosis and death irrespective of cause) curves were constructed using the Kaplan-Meier method, with log-rank test (univariable analysis) and Cox regression analysis, for standard clinicopathological variables (age, gender, histological subtype, pathological stage) and methylation level of candidate genes. For this purpose, candidate gene methylation levels were classified as low or high using the 75th percentile methylation value of each gene as cutoff, and age, stage and histological subtype were dichotomized as age $<75$ vs $\geq 75$, stage I and II vs stage III and IV and pRCC vs ccRCC.

Statistical significance level was set at $\mathrm{p}<0.05$ (twosided). Analysis was performed using IBM ${ }^{\circledR}$ SPSS ${ }^{\circledR}$ Statistics for Windows, version 22.0 (SPSS, Chicago, IL, USA). Graphs were built using GraphPad Prism 6.0 software for Windows (GraphPad Software Inc., La Jolla, CA, USA).

\section{Results}

\section{Promoter methylation analysis by qMSP}

Tumor samples were categorized as HOXA9 or OXR1 methylated using the respective highest methylation ratio value observed in normal/control samples as cutoff (14.11 for HOXA9 and 1577.45 for OXR1). Using these criteria, 73 and $87 \%$ of tumor samples were considered 
hypermethylated at HOXA9 and OXR1 promoters, respectively. Considering each subtype, the highest HOXA9 promoter methylation frequency was found in oncocytomas $(93 \%)$, followed by ccRCC $(70 \%)$, chRCC $(67 \%)$ and pRCC (60\%), whereas the highest OXR1 promoter methylation frequency was found in pRCC (93\%), followed by ccRCC and oncocytoma (87\%), and then chRCC (80\%).

Levels in RCTs were significantly higher than in normal kidney ( $\mathrm{p}<0.001$ ) (Fig. 1a). Moreover, HOXA9 and OXR1 promoter methylation also differed between benign ( $\mathrm{RO}$ ) and malignant $(\mathrm{RCC})$ renal cell tumors $(\mathrm{p}=0.011$ and $\mathrm{p}=0.009$, respectively) (Fig. 1b). Among RCT subtypes, OXR1 methylation were significantly higher in ccRCC compared to the remaining three subtypes $(\mathrm{p}<0.001$ for all), and also in pRCC compared to chRCC ( $<<0.001)$ (Fig. 1c2). Concerning HOXA9, promoter methylation levels were only significantly higher in RO compared to $\operatorname{chRCC}(\mathrm{p}=0.004)$ (Fig. 1c1).

\section{Diagnostic performance of candidate biomarkers}

Both high HOXA9 and OXR1 promoter methylation levels discriminated normal from tumour samples with good sensitivity and high specificity (73 and 89\% for HOXA9 and 87 and $100 \%$ for OXR1, respectively)
(Table 2). High OXR1 promoter methylation levels also discriminated ccRCC from the remaining RCTs tested (pRCC, chRCC and RO) with $80 \%$ sensitivity and 93\% specificity (AUC $=0.847$ ) (Table 2; Fig. 2a).

Considering these results and those that we previously reported for MST1R [14], a gene panel combining OXR1 and MST1R gene promoter methylation was tested, and diagnostic performance increased for discrimination between ccRCC vs RCTs, displaying 90\% sensitivity and $98 \%$ specificity (AUC $=0.939$ ) (Table 2 ; Fig. $2 b$ ). Then, using HOXA9 promoter methylation levels, RO could be discriminated from pRCC and chRCC with 77\% sensitivity and $73 \%$ specificity (Table 2; Fig. 2c). A proposed combined use of these biomarkers is depicted in Fig. 3.

\section{Clinicopathological correlates}

Relevant clinical and pathological data of the 120 RCT patients included in this study are depicted in Table 3 $[14,25]$. The 9 patients from which normal kidney tissue was retrieved presented a median age of 69 years (range: 20-83), and 6 (67\%) were males. No statistically significantly differences between RCT and normal kidney samples were found for age $(\mathrm{p}=0.24)$ nor gender $(0.453)$.

OXR1 and HOXA9 promoter methylation levels did not correlate with age $(\mathrm{p}=0.08$ and $\mathrm{p}=0.18$, respectively)
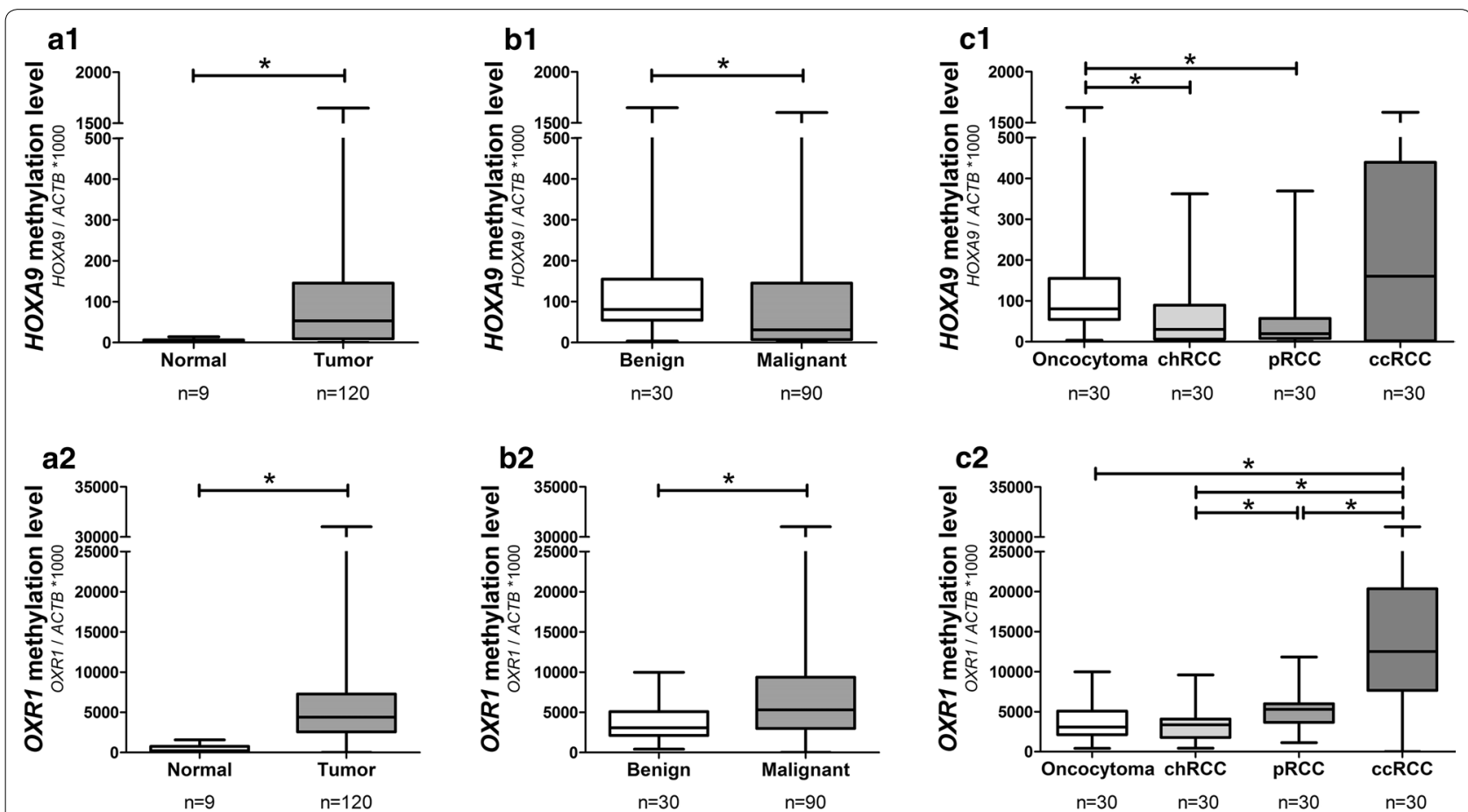

Fig. 1 OXR1 and HOXA9 promoter methylation levels. Methylation levels in 9 normal renal tissue and 120 RCT samples for HOXA9 (a1) and OXR1 (a2); in 30 benign (oncocytoma) and 90 malignant (renal cell carcinoma) for HOXA9 (b1) and OXR1 (b2); and in the four RCT subtypes HOXA9 (c1) and OXR1 (c2). Target gene methylation level = target gene mean quantity/ACTB mean quantity * 1000). chRCC chromophobe renal cell carcinoma, pRCC papillary renal cell carcinoma, cCRCC clear cell renal cell carcinoma, RCT renal cell tumour 
Table 2 Diagnostic performance of OXR1, OXR1\&MST1R, and HOXA9 promoter methylation in different clinical settings

\begin{tabular}{llllll}
\hline & SE (\%) & SP (\%) & PPV (\%) & NPV (\%) & Accuracy (\%) \\
\hline $\begin{array}{c}\text { Normal vs tumour } \\
\text { OXR1 methyla- } \\
\text { tion }\end{array}$ & 87 & 100 & 100 & 36 & 88 \\
$\begin{array}{c}\text { OXR1\&MST1R } \\
\text { methylation } \\
\text { HOXA9 methyla- } \\
\text { tion }\end{array}$ & 98 & 100 & 100 & 75 & 98 \\
$\begin{array}{c}\text { CCRCC vS RCT } \\
\text { OXR1 methyla- } \\
\text { tion }\end{array}$ & 80 & 99 & 99 & 20 & 74 \\
$\begin{array}{c}\text { OXR1\&MST1R } \\
\text { methylation }\end{array}$ & 90 & 98 & 93 & 97 & 96 \\
$\begin{array}{l}\text { RO vs pRCC\&ChRCC } \\
\text { HOXA9 methyla- } \\
\text { tion }\end{array}$ & 20 & 95 & 67 & 70 & 70 \\
\hline
\end{tabular}

SE sensitivity, $S P$ specificity, $P P V$ positive predictive value, NPV negative predictive value, $R C T$ renal cell tumour, $C C R C C$ clear cell renal cell carcinoma, pRCC papillary renal cell carcinoma, $C h R C C$ chromophobe renal cell carcinoma, $R O$ renal oncocytoma

or gender $(\mathrm{p}=0.46$ and $\mathrm{p}=0.15$, respectively). Considering all RCCs, methylation levels of OXR1 and HOXA9 were not associated with stage $(\mathrm{p}=0.143$ and $\mathrm{p}=0.254$ respectively) nor with the development of metastasis ( $p=0.055$ and $p=0.467$ respectively). In ccRCC and pRCC, OXR ( $\mathrm{p}=0.008)$, but not HOXA9, promoter methylation levels associated with nuclear grade. Considering each histological subtype separately, higher OXR1 promoter methylation levels were observed in high (3 and 4) grade tumours (median: 16,714; interquartile range: $11,993-21,817)$ compared to low $(1$ and 2$)$ grade tumours (median: 7300; interquartile range: $355-10,715$ ) in ccRCC only $(\mathrm{p}=0.005)$ (Fig. 4).
No significant differences were found for age, gender or stage in ccRCCs that presented higher vs lower $O X R 1$ methylation levels (cutoff $=$ median value of OXR1 promoter methylation levels distribution, $\mathrm{p}=0.486$, $\mathrm{p}=0.700$ and $\mathrm{p}=0.109$, respectively).

\section{Survival analysis}

During follow-up [median (range): 60 months (2-392 months)], 12 (13\%) patients died from RCC and 17 (19\%) developed metastatic disease.

Stages III and IV were associated with shorter cancer specific survival [HR: $13.5(3-62), \mathrm{p}=0.001]$, diseasefree survival [HR: $4.5(1.7-12), \mathrm{p}=0.002]$ and overall survival [HR: $2.8(1.3-6.1), \mathrm{p}=0.01$ ] when compared to stages I and II, as expected. Considering only ccRCC and pRCC, the subtypes that most frequently display metastatic spread, pRCC was associated with shorter overall survival [HR: 2.7 (1.1-6.6), $\mathrm{p}=0.033$ ].

Higher OXR1 or HOXA9 promoter methylation levels were not associated with worse disease specific, disease free or overall survival.

\section{Discussion}

Renal cell tumours, the most frequent (85-90\%) kidney tumours, were classically diagnosed in advanced stage (IV), with large size, presence of metastasis and dismal prognosis when compared to kidney-confined tumours, which can usually be cured by complete surgical resection. However, with the increasing number of abdominal imaging studies performed due to unrelated symptoms, the number of incidentally diagnosed tumours has increased, posing new clinical challenges. These incidental tumours tend to be smaller $(<5 \mathrm{~cm})$ and kidneyconfined, allowing complete surgical resection by partial nephrectomy in a high proportion of cases, or even alternative therapeutic strategies, including cryoablation or
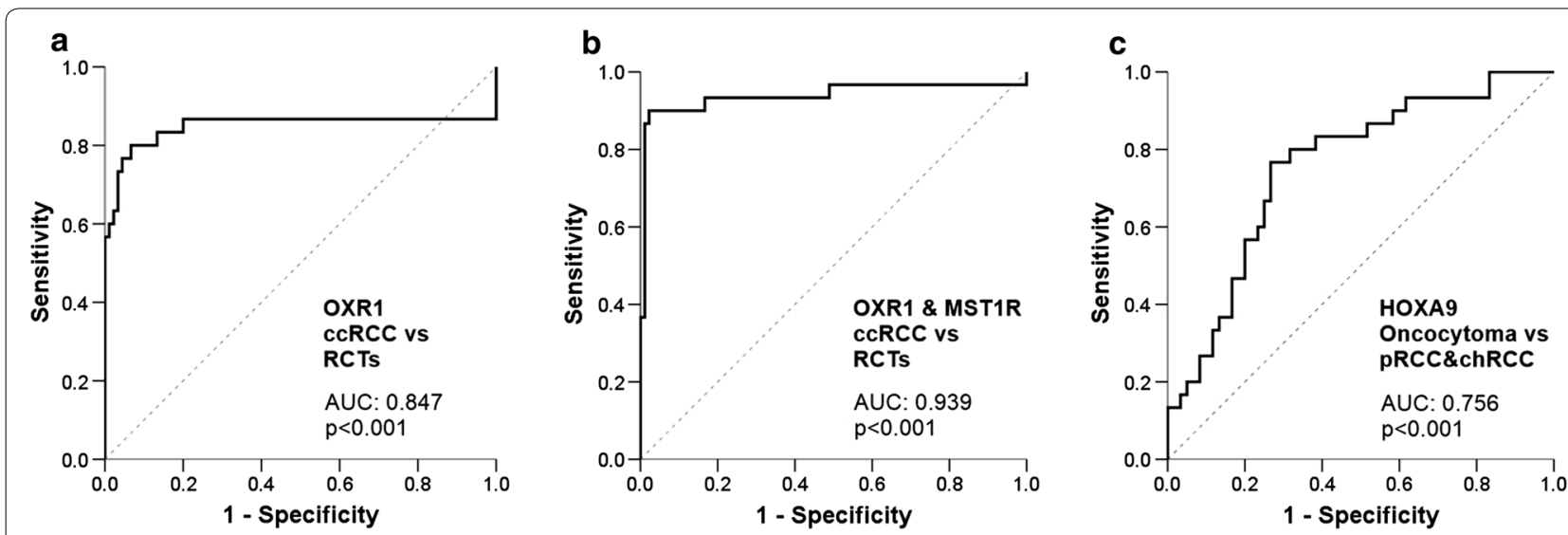

Fig. 2 ROC curves for OXR1, OXR1\&MST1R and HOXA9 promoter methylation levels in different clinical settings. ROC curves for clear cell renal cell carcinoma (cCRCC) versus the remaining renal cell tumours (RCT) for OXR1 (a) and for OXR1\&MST1R (b), and for oncocytoma versus papillary (pRCC) and chromophobe (chRCC) renal cell carcinoma for HOXA9 (c) 

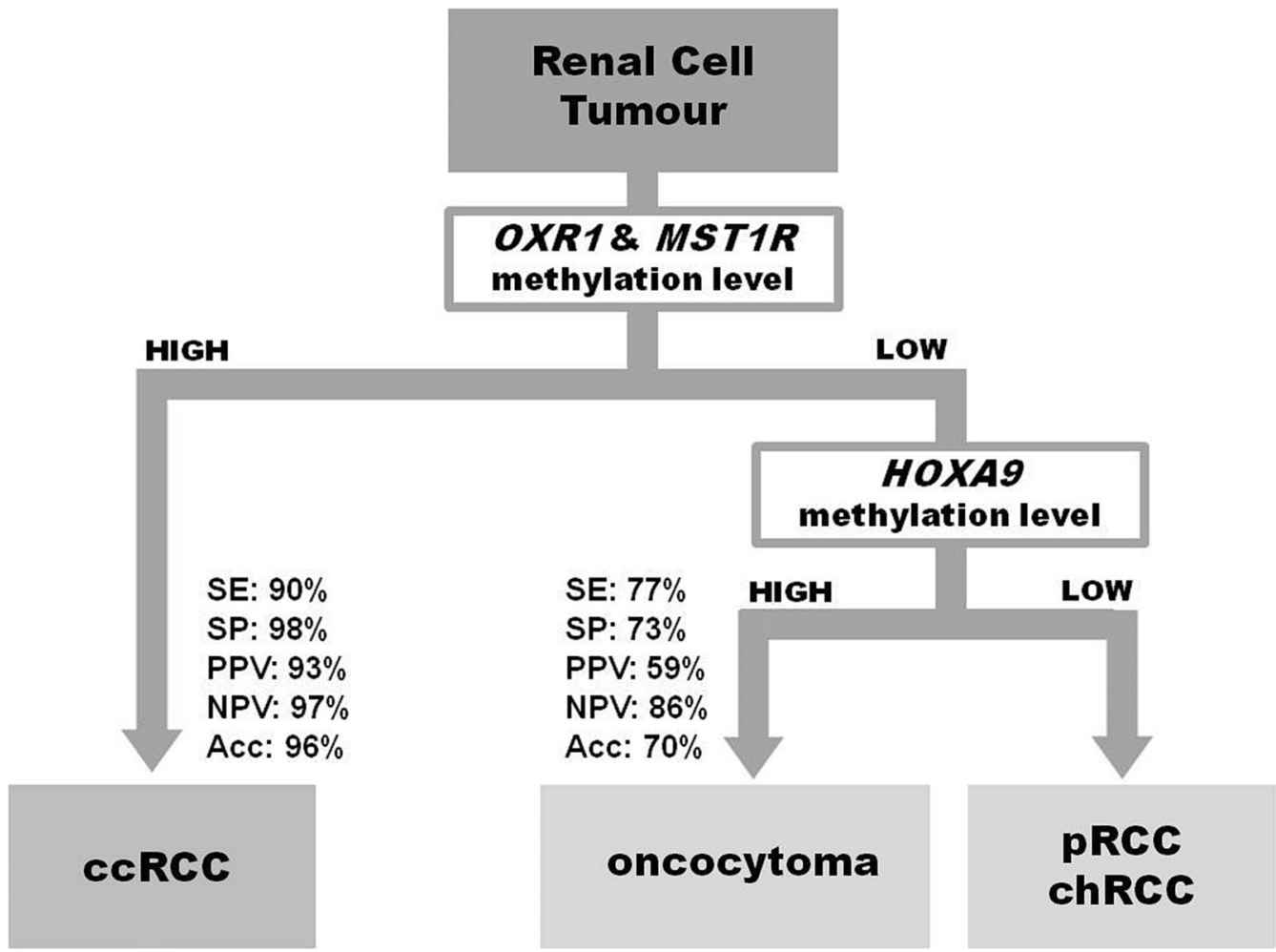

Fig. 3 Proposed algorithm for discriminating among renal cell tumours in tissue samples. High promoter methylation levels of OXR1 combined with MST1R allowed identification of renal cell tumours (RCT) from normal renal tissue, and of clear cell renal cell carcinoma (ccRCC) from the remaining renal cell tumours (RCT). Then, a high promoter methylation level of HOXA9 allowed the identification of oncocytoma from papillary (pRCC) and chromophobe (chRCC) renal cell carcinoma. SE sensitivity, SP specificity, PPV positive predictive value, NPV negative predictive value, Acc accuracy

radiofrequency ablation. In these cases, renal mass biopsy is mandatory, for adequate risk stratification, which requires accurate diagnosis $[4,26]$. However, despite tumour subtype identification being globally accurate $(>90 \%)$ in renal mass biopsy, it is non-diagnostic in approximately $15 \%$ of patients, more frequently in small renal tumours. Moreover, it could underestimate tumour grade and stage in 25 and $5-10 \%$ of patients, respectively, and fail identification of pathologic features associated with aggressiveness (e.g., sarcomatoid differentiation) mostly due to sampling limitations [27]. In this context, diagnostic epigenetic biomarkers, including promoter methylation, might be clinically useful, mainly in patients considered for ablative techniques, in which renal mass biopsy is the sole available source of tumor material [27, 28]. Although several genes were consistently reported to be hypermethylated in RCC, and methylation array based studies reported different methylation patterns in distinct RCT subtypes [22, 23], validation in independent series has been seldom performed.

For this study, we selected three genes-OXR1, methylated in ccRCC and pRCC [22]; HOXA9, reported as differentially methylated in chRCC and oncocytomas [23]; and MST1R, highly methylated in ccRCC, that we previously shown to accurately identify ccRCC [14] - to assess their diagnostic performance in an independent series of 120 RCTs. Using robust methylation-specific primers for each gene promoter and performing quantitative methylation-specific PCR, we found that $O X R 1$ and MST1R promoter methylation discriminated between normal renal tissue and renal cell tumours with high specificity. Moreover, higher OXR1 and MST1R methylation levels were characteristic of ccRCC ( $90 \%$ sensitivity and $98 \%$ specificity). Thus, this biomarker panel might be useful as ancillary diagnostic tool in renal mass biopsies with ambiguous morphological findings or limited tissue for microscopic evaluation. Furthermore, in patients with low OXR1 and MST1R methylation level (NPV: 97\%), HOXA9 methylation level distinguished oncocytoma from chRCC and pRCC. This biomarker might be useful in cases in which Hale's colloidal iron and immunohistochemistry (CK7, CD15) do not allow for a confident differential diagnosis between oncocytoma and chRCC [5]. This information might be clinically useful, not only 
Table 3 Clinical and pathological features of the 120 RCT patients included in the study

\begin{tabular}{|c|c|}
\hline & Tumour \\
\hline Number of patients, $\mathrm{n}$ & 120 \\
\hline Age, median (range) & $60(29-83)$ \\
\hline \multicolumn{2}{|l|}{ Gender, n (\%) } \\
\hline Male & $73(61)$ \\
\hline Female & $47(39)$ \\
\hline \multicolumn{2}{|l|}{ Histological subtype, n (\%) } \\
\hline Clear cell RCC & $30(25)$ \\
\hline Papillary RCC & $30(25)$ \\
\hline Chromophobe RCC & $30(25)$ \\
\hline Oncocytoma & $30(25)$ \\
\hline \multicolumn{2}{|l|}{ Pathological stage, n (\%) } \\
\hline Stage I & $47(39)$ \\
\hline Stage II & $19(16)$ \\
\hline Stage III & $21(17.5)$ \\
\hline Stage IV & $3(2.5)$ \\
\hline n.a. (oncocytoma) & $30(25)$ \\
\hline \multicolumn{2}{|l|}{ Nuclear grade, n (\%) } \\
\hline Grade 1 & $3(2.5)$ \\
\hline Grade 2 & $23(19)$ \\
\hline Grade 3 & $29(24.5)$ \\
\hline Grade 4 & $5(4)$ \\
\hline n.a. (chRCC and oncocytoma) & $60(50)$ \\
\hline \multicolumn{2}{|l|}{ Metastasis during follow-up } \\
\hline Clear cell RCC & $9(7.5)$ \\
\hline Papillary RCC & $7(5.8)$ \\
\hline Chromophobe RCC & $1(0.8)$ \\
\hline
\end{tabular}

$R C C$ renal cell carcinoma, $c h R C C$ chromophobe renal cell carcinoma, n.a. not applicable

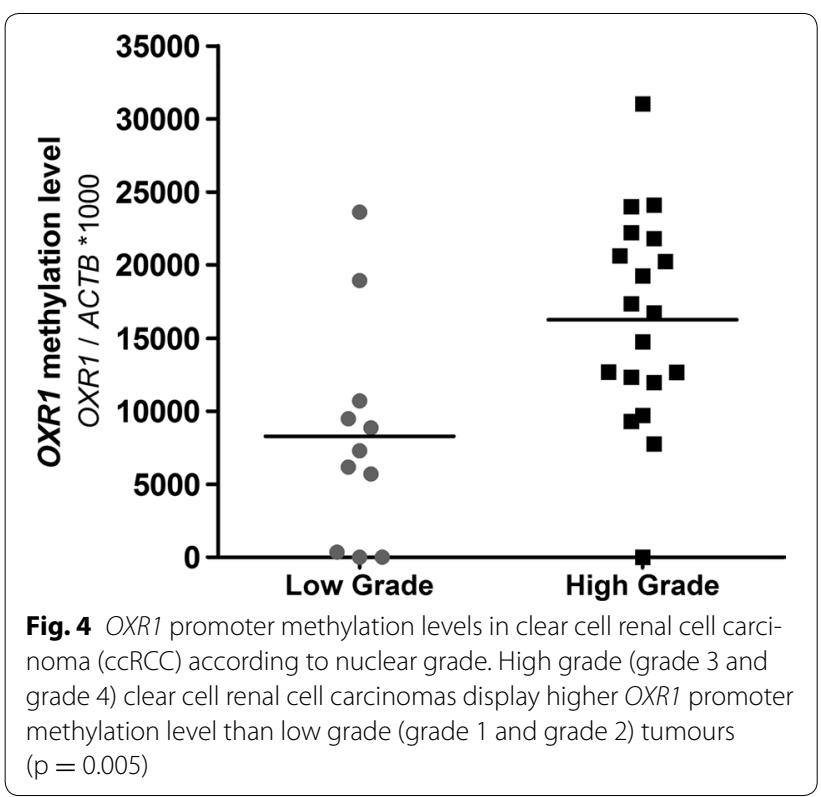

to decide the best therapeutic strategy but also to select patients for active surveillance protocols [26, 27].

These results compare well with the reported performance of other DNA methylation-based biomarkers. PCDH17 and TCF21 promoter methylation identified renal cell tumours with $67 \%$ sensitivity and $100 \%$ specificity [29], but $O X R 1$ and $M S T 1 R$ were equally specific (100\%) but more sensitive (98\%) in the distinction between RCT and normal renal tissue. PTGS2 was reported to distinguish ccRCC from the remaining RCTs subtypes with $46 \%$ sensitivity and $91 \%$ specificity [13], and we demonstrated that OXR1 and MST1R reached a superior performance in all validity estimates. Moreover, RASSF1A hypermethylation was shown to discriminate pRCC from normal renal tissue with $87.5 \%$ sensitivity and $73.3 \%$ specificity, although comparison with other RCT subtypes was not undertaken [30]. Recently, an Illumina Infinium HumanMethylation450 (HM450) DNA methylation model for subtype prediction (encompassing angiomyolipoma, oncocytoma, ccRCC, pRCC and chRCC) that includes 59 variables (2 for angiomylolipoma, 9 for oncocytoma, 11 for normal kidney, 13 for ccRCC, 14 for pRCC and 10 for chRCC) was reported [31]. This model predicted for malignancy in $93 \%$ of samples, the correct subtype in $85 \%$ of RCT samples and $91 \%$ of ccRCC in the validation cohort (272 ex vivo core biopsies) [31]. Although we used a simpler and less expensive approach, correct ccRCC identification was reached in $98 \%$ of samples with the two-gene panel. Several studies focused on detection of aberrant promoter methylation in urine samples for RCT diagnosis. Nonetheless, the sensitivity was significantly lower than in tissue samples [29, 32, 33], and additional technical developments are warranted. Other epigenetic biomarker panels allowing for discrimination among RCT subtypes have been reported. A microRNA panel comprising miR-141 and miR-200b identified RCTs with high specificity and sensitivity (100 and 99\%, respectively), discriminating oncocytoma from RCC and from chRCC with 86 and $90 \%$ sensitivity, respectively [34]. This performance is similar to that of OXR1 and MST1R methylation panel for RCT (98\% sensitivity, $100 \%$ specificity), although this panel did not perform as well concerning oncocytoma vs RCC in general.

Interestingly, some associations between promoter methylation levels and clinicopathological parameters were disclosed, although no impact in patient survival was apparent, probably due to the low number of events during follow-up. Indeed, high grade ccRCC displayed higher OXR1 methylation levels than low grade ccRCC. This might be of clinical relevance as the most recently published biopsy series reveal high accuracy for RCT subtype identification, but poor reproducibility 
for tumour grading [4, 27]. Tumour grade is an important criterion for risk stratification of small renal masses, contributing for decisions about clinical management, i.e., either recruitment for active surveillance protocols, or selection for nephrectomy or ablative therapies [35]. Hence, a diagnostic biomarker that, in addition to histological subtype, also conveys information about tumor aggressiveness might improve risk stratification algorithms in biopsies from small renal masses.

The main limitations of this study concerns to the use of fresh-frozen tissue from renal tumours for molecular analysis, requiring validation in formalin-fixed paraffin embedded tissues from biopsy specimens before clinical implementation. Furthermore, the sensitivity and specificity for identification of oncocytoma requires improvement, eventually through the addition of another marker. Finally, the limited number of kidney cancerrelated deaths and progression events impaired survival analysis.

\section{Conclusions}

A panel including OXR, MST1R and HOXA9 promoter methylation might be useful for positive identification of RCT, as well as for discrimination among subtypes. This panel could be used as ancillary diagnostic tool in the setting of renal mass biopsy, in which the amount of tissue available for histopathological examination may preclude a definitive diagnosis. Moreover, the panel might also improve risk stratification of patients harboring small renal masses, assisting clinicians in defining the best therapeutic strategy. Nevertheless, validation in larger independent cohorts is warranted to confirm the clinical potential of this gene methylation panel.

\section{Abbreviations}

RCT: renal cell tumour; RCC: renal cell carcinoma; $c C R C C$ : clear cell renal cell carcinoma; pRCC: papillary renal cell carcinoma; chRCC: chromophobe renal cell carcinoma; RO: renal oncocytoma; OXR1: oxidation resistance gene 1; HOXA9: homeobox A9; MST1R: macrophage stimulating 1 receptor; ROC: receiver operating characteristic; AUC: area under the curve; SE: sensitivity; SP: specificity; PPV: positive predictive value; NPV: negative predictive value; CNV: copy number variation.

\section{Authors' contributions}

Conceived and designed the experiments: ASPL, RH, CJ. Performed the experiments: ASPL, PCP and MJF. Data analysis and interpretation: ASPL, LA, RH and CJ. Contributed reagents/material/analysis: FL, JO, RH, CJ. Manuscript preparation: ASPL, RH and CJ. All authors read and approved the final manuscript.

\footnotetext{
Author details

${ }^{1}$ Cancer Biology and Epigenetics Group, IPO Porto Research Center (CI-IPOP), Portuguese Oncology Institute of Porto (IPO Porto), Research Center-LAB 3, F Bdg., 1st Floor, Rua Dr António Bernardino de Almeida, 4200-072 Porto, Portugal. ${ }^{2}$ Department of Pathology, Portuguese Oncology Institute of Porto (IPO Porto), Porto, Portugal. ${ }^{3}$ Department of Epidemiology, Portuguese Oncology Institute of Porto (IPO Porto), Porto, Portugal. ${ }^{4}$ Department of Urology, Portuguese Oncology Institute of Porto (IPO Porto), Porto, Portugal. ${ }^{5}$ Department of Pathology and Molecular Immunology, Institute of Biomedical Sciences Abel Salazar (ICBAS), University of Porto, Porto, Portugal.
}

Acknowledgements

Not applicable.

\section{Competing interests}

The authors declare that they have no competing interests.

\section{Availability of data and materials}

The datasets used and/or analyzed during the current study available from the corresponding author on reasonable request.

\section{Ethics approval and consent to participate}

This study was approved by the Institutional Review Board (Comissão de Ética para a Saúde) of Portuguese Oncology Institute-Porto, Portugal (CES518/2010).

\section{Funding}

This study was funded by research grants from Research Center of Portuguese Oncology Institute-Porto (CI-IPOP 4-2012 and CI-IPOP 27) and from Associação Portuguesa de Urologia (APU-2010). ASP-L was supported by FCT-Fundação para a Ciência e a Tecnologia fellowship (SFRH/SINTD/94217/2013).

\section{Publisher's Note}

Springer Nature remains neutral with regard to jurisdictional claims in published maps and institutional affiliations.

Received: 18 April 2017 Accepted: 21 June 2017

Published online: 29 June 2017

\section{References}

1. Morris MR, Latif F. The epigenetic landscape of renal cancer. Nat Rev Nephrol. 2016;13:47-60.

2. Moch H, Humphrey PA, Ulbright TM, Reuter VE, editors. WHO classification of tumours of the urinary system and male genital organs. Lyon: IARC; 2016

3. Fernandez-Acenero MJ, Cazorla A, Manzarbeitia F. Immunohistochemistry for the differential diagnosis of renal tumors with oncocytic features. Urol Oncol. 2011:29:545-9.

4. Tsivian M, Rampersaud EN Jr, del Pilar Laguna Pes M, Joniau S, Leveillee RJ, Shingleton WB, Aron M, Kim CY, DeMarzo AM, Desai MM. Small renal mass biopsy — how, what and when: report from an international consensus panel. BJU Int. 2014;113:854-63.

5. Al-Ahmadie HA, Alden D, Fine SW, Gopalan A, Touijer KA, Russo P, Reuter VE, Tickoo SK. Role of immunohistochemistry in the evaluation of needle core biopsies in adult renal cortical tumors: an ex vivo study. Am J Surg Pathol. 2011;35:949-61.

6. Allis $C D$, Jenuwein T. The molecular hallmarks of epigenetic control. Nat Rev Genet. 2016;17:487-500.

7. Jeronimo C, Henrique R. Epigenetic biomarkers in urological tumors: a systematic review. Cancer Lett. 2014;342:264-74.

8. Henrique R, Luis AS, Jeronimo C. The epigenetics of renal cell tumors: from biology to biomarkers. Front Genet. 2012;3:94.

9. la Rosa AH, Acker M, Swain S, Manoharan M. The role of epigenetics in kidney malignancies. Cent Eur J Urol. 2015;68:157-64.

10. Shenoy N, Vallumsetla N, Zou Y, Galeas JN, Shrivastava M, Hu C, Susztak $\mathrm{K}$, Verma A. Role of DNA methylation in renal cell carcinoma. J Hematol Oncol. 2015:8:88.

11. Christoph F, Kempkensteffen C, Weikert S, Kollermann J, Krause H, Miller K, Schostak M, Schrader M. Methylation of tumour suppressor genes APAF-1 and DAPK-1 and in vitro effects of demethylating agents in bladder and kidney cancer. Br J Cancer. 2006;95:1701-7.

12. Christoph F, Weikert S, Kempkensteffen C, Krause H, Schostak M, Kollermann J, Miller K, Schrader M. Promoter hypermethylation profile of kidney cancer with new proapoptotic p53 target genes and clinical implications. Clin Cancer Res. 2006;12:5040-6.

13. Costa VL, Henrique R, Ribeiro FR, Pinto M, Oliveira J, Lobo F, Teixeira MR, Jeronimo C. Quantitative promoter methylation analysis of multiple cancer-related genes in renal cell tumors. BMC Cancer. 2007;7:133. 
14. Pires-Luís AS, Lobo F, Vieira-Coimbra M, Costa-Pinheiro P, Antunes L, Oliveira J, Henrique R, Jerónimo C. MST1R methylation as a diagnostic biomarker in renal cell tumors. Acta Urol Port. 2015;32:64-70.

15. Morris MR, Gentle D, Abdulrahman M, Maina EN, Gupta K, Banks RE, Wiesener MS, Kishida T, Yao M, Teh B, et al. Tumor suppressor activity and epigenetic inactivation of hepatocyte growth factor activator inhibitor type 2/SPINT2 in papillary and clear cell renal cell carcinoma. Cancer Res. 2005;65:4598-606.

16. de Caceres II, Dulaimi E, Hoffman AF, Al-Saleem T, Uzzo RG, Cairns P. Identification of novel target genes by an epigenetic reactivation screen of renal cancer. Cancer Res. 2006:66:5021-8.

17. Kagara I, Enokida H, Kawakami K, Matsuda R, Toki K, Nishimura H, Chiyomaru T, Tatarano S, Itesako T, Kawamoto K, et al. CpG hypermethylation of the UCHL1 gene promoter is associated with pathogenesis and poor prognosis in renal cell carcinoma. J Urol. 2008;180:343-51.

18. Morris MR, Gentle D, Abdulrahman M, Clarke N, Brown M, Kishida T, Yao M, Teh BT, Latif F, Maher ER. Functional epigenomics approach to identify methylated candidate tumour suppressor genes in renal cell carcinoma. Br J Cancer. 2008;98:496-501.

19. McRonald FE, Morris MR, Gentle D, Winchester L, Baban D, Ragoussis J Clarke NW, Brown MD, Kishida T, Yao M, et al. CpG methylation profiling in VHL related and VHL unrelated renal cell carcinoma. Mol Cancer. 2009;8:31.

20. Morris MR, Ricketts C, Gentle D, Abdulrahman M, Clarke N, Brown M, Kishida T, Yao M, Latif F, Maher ER. Identification of candidate tumour suppressor genes frequently methylated in renal cell carcinoma. Oncogene. 2010;29:2104-17.

21. Morris MR, Ricketts CJ, Gentle D, McRonald F, Carli N, Khalili H, Brown M, Kishida T, Yao M, Banks RE, et al. Genome-wide methylation analysis identifies epigenetically inactivated candidate tumour suppressor genes in renal cell carcinoma. Oncogene. 2011;30:1390-401.

22. Ibragimova I, Slifker MJ, Maradeo ME, Banumathy G, Dulaimi E, Uzzo RG, Cairns P. Genome-wide promoter methylome of small renal masses. PLoS ONE. 2013;8:e77309.

23. Slater AA, Alokail M, Gentle D, Yao M, Kovacs G, Maher ER, Latif F. DNA methylation profiling distinguishes histological subtypes of renal cell carcinoma. Epigenetics. 2013;8:252-67.

24. Patricio P, Ramalho-Carvalho J, Costa-Pinheiro P, Almeida M, Barros-Silva JD, Vieira J, Dias PC, Lobo F, Oliveira J, Teixeira MR, et al. Deregulation of
PAX2 expression in renal cell tumours: mechanisms and potential use in differential diagnosis. J Cell Mol Med. 2013;17:1048-58.

25. Pires-Luis AS, Vieira-Coimbra M, Ferreira MJ, Ramalho-Carvalho J, CostaPinheiro P, Antunes L, Dias PC, Lobo F, Oliveira J, Graca I, et al. Prognostic significance of MST1R dysregulation in renal cell tumors. Am J Cancer Res. 2016;6:1799-811

26. Leao RR, Richard PO, Jewett MA. Indications for biopsy and the current status of focal therapy for renal tumours. Transl Androl Urol. 2015;4:283-93.

27. Blute ML Jr, Drewry A, Abel EJ. Percutaneous biopsy for risk stratification of renal masses. Ther Adv Urol. 2015;7:265-74.

28. Cheng L, Zhang S, MacLennan GT, Lopez-Beltran A, Montironi R. Molecular and cytogenetic insights into the pathogenesis, classification, differential diagnosis, and prognosis of renal epithelial neoplasms. Hum Pathol. 2009;40:10-29.

29. Costa VL, Henrique R, Danielsen SA, Eknaes M, Patricio P, Morais A, Oliveira J, Lothe RA, Teixeira MR, Lind GE, Jeronimo C. TCF21 and PCDH17 methylation: an innovative panel of biomarkers for a simultaneous detection of urological cancers. Epigenetics. 2011;6:1120-30.

30. Ellinger J, Holl D, Nuhn P, Kahl P, Haseke N, Staehler M, Siegert S, Hauser S, Stief CG, Muller SC, Bastian PJ. DNA hypermethylation in papillary renal cell carcinoma. BJU Int. 2011;107:664-9.

31. Chopra S, Liu J, Alemozaffar M, Nichols PW, Aron M, Weisenberger DJ, Collings CK, Syan S, Hu B, Desai M, et al. Improving needle biopsy accuracy in small renal mass using tumor-specific DNA methylation markers. Oncotarget. 2017:8:5439-48.

32. Hoque MO, Begum S, Topaloglu O, Jeronimo C, Mambo E, Westra WH, Califano JA, Sidransky D. Quantitative detection of promoter hypermethylation of multiple genes in the tumor, urine, and serum DNA of patients with renal cancer. Cancer Res. 2004;64:5511-7.

33. Battagli C, Uzzo RG, Dulaimi E, de Caceres II, Krassenstein R, Al-Saleem T, Greenberg RE, Cairns P. Promoter hypermethylation of tumor suppressor genes in urine from kidney cancer patients. Cancer Res. 2003;63:8695-9.

34. Silva-Santos RM, Costa-Pinheiro P, Luis A, Antunes L, Lobo F, Oliveira J, Henrique R, Jeronimo C. MicroRNA profile: a promising ancillary tool for accurate renal cell tumour diagnosis. Br J Cancer. 2013;109:2646-53.

35. Richard PO, Jewett MA, Tanguay S, Saarela O, Liu ZA, Pouliot F, Kapoor A, Rendon R, Finelli A. Safety, reliability and accuracy of small renal tumour biopsies: results from a multi-institution registry. BJU Int. 2017;119:543-9.

\section{Submit your next manuscript to BioMed Central and we will help you at every step:}

- We accept pre-submission inquiries

- Our selector tool helps you to find the most relevant journal

- We provide round the clock customer support

- Convenient online submission

- Thorough peer review

- Inclusion in PubMed and all major indexing services

- Maximum visibility for your research

Submit your manuscript at www.biomedcentral.com/submit
() BioMed Central 